\title{
Down-regulation of Inositol Polyphosphate 4-Phosphatase Type II Expression in Colorectal Carcinoma
}

\author{
JI-YOUN SUNG ${ }^{1}$, KIYONG NA $^{2}$ and HYUN-SOO KIM ${ }^{2}$ \\ ${ }^{1}$ Department of Pathology, Kyung Hee University School of Medicine, Seoul, Republic of Korea; \\ ${ }^{2}$ Department of Pathology, Severance Hospital, Yonsei University College of Medicine, Seoul, Republic of Korea
}

\begin{abstract}
Background/Aim: Aberrant expression of survival signaling pathways causes deregulation of cellular proliferation and resistance to apoptosis, and plays a crucial role in the development, progression and metastasis of cancer. Inositol polyphosphate 4-phosphatase type II (INPP4B) negatively regulates phosphatidylinositol 3-kinase signaling and has a tumor-suppressive role in several human malignancies. Materials and Methods: We analyzed the expression levels of INPP $4 B \mathrm{mRNA}$ and protein in colorectal carcinoma $(C R C)$ cell lines and tissue samples using western blot, quantitative real-time reverse-transcriptase polymerase chain reaction, and immunohistochemical staining. Results: Western blot analysis revealed that the CRC cell lines HCT 116, SW620, DLD-1, and WiDr expressed significantly lower levels of INPP4B protein than the normal colonic epithelial cell lines CCD 841 CoTr and FHC. Consistent with these results, INPP4B $M R N A$ expression in the CRC cell lines was significantly lower than in the normal colonic epithelial cells. Immunohistochemical staining revealed that normal colonic mucosa displayed uniform and strong-to-moderate INPP4B immunoreactivity, whereas $60.7 \%$ (71/117; $p<0.001)$ and $76.5 \%(62 / 81 ; p<0.001)$ of the primary and metastatic CRC tissue samples exhibited reduced INPP $4 B$ expression, respectively. Conclusion: Our results indicate that INPP4B is down-regulated in CRC and that INPP4B is involved in the development and progression of CRC.
\end{abstract}

Despite the availability of preventive screening, colorectal carcinoma (CRC) remains one of the most commonly diagnosed malignancies, even in the developed world. It is

Correspondence to: Hyun-Soo Kim, Department of Pathology, Severance Hospital, Yonsei University College of Medicine, 50-1, Yonsei-ro, Seodaemun-gu, Seoul 03722, Republic of Korea. Tel: +82 222281794, +82 23620860, e-mail: hyunsookim@yuhs.ac

Key Words: Colon, colorectal carcinoma, inositol polyphosphate 4phosphatase type II, metastasis, immunohistochemistry. the fourth most common cancer in Western countries and second leading cause of cancer-related deaths in Europe and North America (1-3). In the Republic of Korea, CRC is the third most common cancer and fourth leading cause of cancer-related deaths (4). Although operative techniques and cytotoxic drugs, as well as more thorough understanding of the molecular carcinogenesis, are being continually refined, the prognosis of patients with CRC remains poor because of locoregional recurrence, lymph node metastasis, and distant metastasis. The pathogenesis of CRC is heterogeneous at the molecular level, and such differences appear to influence behavior and dictate the likelihood of response to both traditional cytotoxic drugs and newer targeted therapeutic agents. It is therefore important to provide accurate histopathological, immunohistochemical, and molecular features of tumors that may impact treatment decisions of oncologists and surgeons.

Identifying patients at high risk of recurrence or metastasis conventionally depends on clinical and pathological parameters, such as tumor stage, invasion depth, mural perforation or invasion of adjacent organs, and metastasis to regional lymph nodes or distant organs. However, the current staging system is limited in that it cannot offer a prognosis for individual patients $(3,5)$. In order to improve the outcomes of patients with $\mathrm{CRC}$, it is crucial to identify cancer-related genes that can serve as diagnostic or predictive biomarkers for individualize therapy.

Aberrant expression of survival-signaling pathways causes deregulation of cellular proliferation and resistance to apoptosis and plays a crucial role in cancer development, progression, metastasis, and treatment resistance (6-8). In CRC, activation of the phosphatidylinositol 3-kinase (PI3K) pathway is particularly important because many common genetic and epigenetic abnormalities in the disease, such as amplification of epidermal growth factor receptor, activating mutations of Kirsten ras proto-oncogene (KRAS), GTPase, and loss of phosphatase and tensin homolog deleted on chromosome 10 (PTEN), converge to activate PI3K signaling $(9,10)$. Binding of extracellular growth factors to receptor 
tyrosine kinases results in the recruitment of PI3K to plasma membrane-anchored receptors where it is activated, leading to increased production of phosphatidylinositol 3,4bisphosphate and phosphatidylinositol 3,4,5-trisphosphate [PI $(3,4,5) \mathrm{P} 3]$, which in turn bind to and activate multiple downstream effectors $(6,11,12)$. Among them, AKR mouse thymoma kinase (AKT) is activated by two phosphorylation events at Thr308 and Ser473 involving phosphoinositidedependent kinase 1 and the mammalian target of rapamycin complex 2, respectively $(13,14)$. Activated AKT then phosphorylates a large array of substrates to contributes to carcinogenesis $(9,15)$.

Activation of PI3K signaling is negatively regulated by three classes of inositol polyphosphate phosphatases (16-21). PTEN dephosphorylates the 3-position of PI(3,4,5)P3 to generate $\mathrm{PI}(4,5) \mathrm{P} 2$, whereas 5-phosphatases, such as $\mathrm{V}$-src sarcoma (Schmidt-Ruppin A-2) viral oncogene (SRC) homology 2 domain-containing inositol 5-phosphatase and $\mathrm{PI}(4,5) \mathrm{P} 2$ 5-phosphatase A/proline-rich inositol polyphosphate phosphatase, dephosphorylate the 5-position of $\mathrm{PI}(3,4,5) \mathrm{P} 3$ to produce $\mathrm{PI}(3,4) \mathrm{P} 2$. The latter is in turn subjected to dephosphorylation by inositol polyphosphate 4phosphatase type I and type II (INPP4B) at the 4-position to generate $\mathrm{PI}(3) \mathrm{P}$, thus terminating $\mathrm{PI} 3 \mathrm{~K}$ signaling $(16,22)$.

In addition to a well-established tumor suppressor PTEN $(18,19)$, some 5-phosphatases and INPP4B are tumorsuppressive through inhibition of PI3K signaling in several human malignancies $(6,16,17,20,21,23)$. However, the role of INPP4B in CRC remains largely unknown. Existing evidence for the important role of INPP4B in inhibiting tumor progression and metastasis prompted us to examine its expression in CRC. In this study, we investigated the expression of INPP4B in CRC cell lines and tissue samples.

\section{Materials and Methods}

Cell culture. Human normal colonic epithelial cell lines, CCD 841 CoTr, and FHC, and human CRC cell lines, HCT 116, SW620, DLD-1, and WiDr, were purchased from the American Type Culture Collection (Manassas, VA, USA) and maintained in Dulbecco's modified Eagle's in edium (DMEM; Gibco, Life Technologies, Grand Island, NY, USA) or Roswell Park Memorial Institute (RPMI)-1640 medium (Gibco) supplemented with 10\% heatinactivated fetal bovine serum, $100 \mathrm{U} / \mathrm{ml}$ penicillin, and $100 \mu \mathrm{g} / \mathrm{ml}$ streptomycin (Gibco). All cell lines examined were cultured in a humidified atmosphere of $5 \%$ carbon dioxide at $37^{\circ} \mathrm{C}$.

cDNA synthesis. RNase-free DNase I treatment was carried to remove contaminating genomic DNA from purified total RNA. Isolated total RNA was diluted to $1 \mathrm{mg} / \mathrm{ml}$ with sterile diethylpyrocarbonate-treated water and $2.5 \mathrm{ml}$ was added to reactions containing $1 \times$ DNase I buffer and $1 \mathrm{U}$ DNase I (final volume, $10 \mathrm{ml}$ ). After incubation at $37^{\circ} \mathrm{C}$ for $30 \mathrm{~min}$, reactions were stopped at $70^{\circ} \mathrm{C}$ for $10 \mathrm{~min}$. DNase I-treated RNA was reversetranscribed into first-strand cDNA using random primers. DNase I- treated RNA $(1 \mu \mathrm{g})$ and random primers $(250 \mathrm{ng})$ were mixed in a $0.5-\mathrm{ml}$ polymerase chain reaction tube and brought to $11 \mathrm{ml}$ with sterile diethylpyrocarbonate-treated water, heated at $65^{\circ} \mathrm{C}$ for $5 \mathrm{~min}$, and chilled quickly on ice. Other reagents were added for a reaction of $20 \mathrm{ml}$ at the following final concentrations: 1× First-Strand Buffer, $10 \mathrm{mM}$ dithiothreitol, $0.5 \mathrm{mM}$ each dNTP, and $200 \mathrm{U}$ Superscript II Reverse Transcriptase (Invitrogen, Carlsbad, CA, USA). Reactions were incubated at $42^{\circ} \mathrm{C}$ for $1 \mathrm{~h}$, heated to $70^{\circ} \mathrm{C}$ for $10 \mathrm{~min}$, and stored at $-20^{\circ} \mathrm{C}$.

Quantitative real-time reverse transcriptase-polymerase chain reaction analysis. After reverse transcription, $3 \mu \mathrm{l}$ was used as a polymerase chain reaction template. Polymerase chain reaction was conducted in $10-\mu$ l solutions containing $1 \times$ SsoFast EvaGreen supermix (Bio-Rad Laboratories, Hercules, CA, USA) and $300 \mathrm{nM}$ each primer. Mixtures were added to 384-well plates for amplification using a CFX Connect Real-Time PCR Detection System (Bio-Rad Laboratories) for $95^{\circ} \mathrm{C}$ for $3 \mathrm{~min}, 95^{\circ} \mathrm{C}$ for $10 \mathrm{~s}$, and $58^{\circ} \mathrm{C}$ for $10 \mathrm{~s}$ for 40 cycles. Amplification patterns were analyzed and threshold cycle numbers $(\mathrm{Ct})$ for each sample were determined using CFX Manager Software (Bio-Rad Laboratories). The primer sequences used for INPP $4 B$ were as follows: forward: 5'-ACT CTA CAC TGC AAG GCC AG-3'; reverse: 5'-ACC CTG TCC CAC TCT TCC TC-3'. The $\Delta \Delta C$ t method was used to calculate the relative expression of the target gene after normalization by $\mathrm{Ct}$ to $\beta$-actin (24). Amplification of the target gene was confirmed by melting-curve analysis and target amplicon size was confirmed by agarose gel electrophoresis. Each sample was assayed in triplicate.

Western blot analysis. CCD 841 CoTr, FHC, HCT 116, SW620, DLD1 , and WiDr cells $\left(5 \times 10^{4}\right.$ cells/well $)$ in 6 -well plates were incubated at $37^{\circ} \mathrm{C}$ in $5 \% \mathrm{CO}_{2}$ in DMEM or RPMI containing $10 \%$ heatinactivated fetal bovine serum. Whole-cell lysates were prepared in radioimmunoprecipitation assay buffer $[50 \mathrm{mM}$ Tris-hydrogen

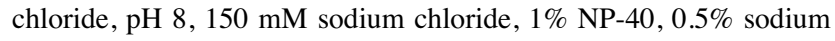
deoxycholate, and $0.1 \%$ sodium dodecyl sulfate] containing protease inhibitors (cOmplete Protease Inhibitor Cocktail Tablet; Roche Applied Science, Basel, Switzerland), and cleared by microcentrifugation $\left(10,000 \times g\right.$ for $20 \mathrm{~min}$ at $\left.4^{\circ} \mathrm{C}\right)$. The resulting lysate was assessed for protein concentration, and $20-30 \mu \mathrm{g}$ of each protein sample was resolved on $12 \%$ sodium dodecyl sulfate-protein gel electrophoresis gel (Bio-Rad Laboratories), and electroblotted onto nitrocellulose membranes (GE Healthcare, Little Chalfont, UK). After $1 \mathrm{~h}$ incubation in blocking solution [5\% nonfat dry milk in Tris-buffered saline with Tween; Pierce, Rockford, IL, USA], the membranes were exposed to the appropriate primary antibodies overnight at $4^{\circ} \mathrm{C}$. The primary antibodies included: anti-INPP4B (1:100, Novus Biologicals, Littleton, CO, USA) and anti- $\beta$-actin (1:5,000, Santa Cruz Biotechology, Santa Cruz, CA, USA). The blots were then washed three times in Trisbuffered saline with Tween and incubated with horseradish peroxidaseconjugated secondary antibodies for $1 \mathrm{~h}$ at room temperature. The results were visualized using an enhanced chemiluminescence system (Amersham, Amersham, UK).

Tissue specimens. CRC tissue samples were obtained from 117 consecutive patients who underwent surgery for primary adenocarcinoma of the colorectum. Corresponding tissue samples from hepatic CRC metastases were also obtained from 81 patients. Two independent Board-certified pathologists reviewed all 
Sung et al: Inositol Polyphosphate 4-phosphatase Type II Down-regulation in Colorectal Carcinoma

Table I. Inositol polyphosphate 4-phosphatase type II (INPP4B) immunoreactivity in colorectal carcinoma (CRC) and normal colonic tissue samples.

\begin{tabular}{lrccccc}
\hline Category & Total, $\mathrm{n}$ & \multicolumn{3}{c}{ INPP4B immunoreactivity, $\mathrm{n}(\%)$} & & \\
\cline { 3 - 5 } & & Negative & Weak & Positive & \\
\hline Normal mucosa & 20 & $0(0.0)$ & $4(20.0)$ & $16(80.0)$ & \\
Primary CRC & 117 & $34(29.1)$ & $37(31.6)$ & $46(39.3)$ & $<0.001^{\mathrm{a}}$ & \\
Metastatic CRC & 81 & $33(40.7)$ & $29(35.8)$ & $19(23.5)$ & $<0.001^{\mathrm{b}}$ & $0.020^{\mathrm{c}}$ \\
\hline
\end{tabular}

aNormal versus primary CRC; ${ }^{b}$ normal versus metastatic CRC; ${ }^{c}$ primary CRC versus metastatic CRC; *significantly different at $p<0.05$.

hematoxylin and eosin-stained slides and selected the most representative slide from each case for immunohistochemical staining. The 81 patients in this study met the following criteria for hepatic resection with curative intent; medical fitness for major hepatic resection; colorectal liver metastasis that resulted in adequately sized, well-vascularized hepatic remnants after hepatic resection; and no signs of extrahepatic metastases in preoperative imaging studies, including chest radiography, abdominal ultrasonography, abdominopelvic computed tomography, and pelvic magnetic resonance imaging $(3,5,25,26)$. No patient underwent preoperative neoadjuvant chemotherapy or neoadjuvant concurrent chemoradiation therapy. The protocols for the use of human tissue were approved by the Institutional Review Board of Kyung Hee University Hospital, Seoul, Republic of Korea (2017-06-070).

Immunohistochemistry. Formalin-fixed tissue was dehydrated in a graded ethanol series and embedded in paraffin. Paraffin blocks were sectioned at $4 \mu \mathrm{m}$ on a standard rotary microtome, and slices were brought from a water bath on cleaned slides. INPP4B protein expression was assessed by immunohistochemistry using the Bond Polymer Intense Detection System (Vision BioSystems, Mount Waverley, Victoria, Australia) following the manufacturer's instructions. The general procedure has been described previously $(3,5,27-31)$. The 4- $\mu \mathrm{m}$ sections of formalin-fixed, paraffinembedded tissue were deparaffinized with Bond Dewax Solution (Vision BioSystems) and an antigen retrieval procedure was performed using Bond Epitope Retrieval Solution (Vision BioSystems) for $30 \mathrm{~min}$ at $100^{\circ} \mathrm{C}$. Endogenous peroxidases were quenched with hydrogen peroxide for $5 \mathrm{~min}$. Sections were incubated for $15 \mathrm{~min}$ at ambient temperature with rabbit polyclonal antibody to INPP4B (1:50, polyclonal; Novus Biologicals). A biotinfree polymeric horseradish peroxidase-linker antibody conjugate system was used with a Bond-maX automatic slide stainer (Vision BioSystems) and visualization was performed using $1 \mathrm{mM} \mathrm{3,3'-}$ diaminobenzidine, $50 \mathrm{mM}$ Tris-hydrogen chloride buffer ( $\mathrm{pH}$ 7.6), and $0.006 \%$ hydrogen peroxide. Sections were counterstained with hematoxylin. Slides were dehydrated following a standard procedure and sealed with coverslips. To minimize interassay variation, positive and negative control samples were included in each run. The positive control was normal colonic tissue. The negative control was prepared by substituting non-immune serum for the primary antibody; no detectable staining was evident.

Immunohistochemical evaluation. Immunohistochemical staining was independently analyzed by two pathologists who were blinded to the clinicopathological data. INPP4B staining intensity in the tumor cells was scored on a scale of 0-3: 0, negative; 1 , weak; 2 , moderate; and 3, strong. The percentage of INPP4B-positive tumor cells was also classified into one of the four categories: $1,0-24 \%$; $2,25-49 \% ; 3,50-74 \%$; and $4,75-100 \%$. The final score was calculated by multiplying the intensity score and percentage score as previously described $(3,5,28,30,31)$. INPP4B immunoreactivity was then classified as negative (score 0 ), weak (score 1-6), and positive (score 8-12) expression. All slides were examined and scored by two Board-certified pathologists who were blinded to the clinicopathological data. Disagreements between the two pathologists were resolved by discussion.

Statistical analysis. We used the unpaired Student's $t$-test to compare the expression levels of INPP4B between normal colonic epithelial and CRC cell lines. Chi-square or Fisher's exact tests were performed to compare INPP4B immunoreactivity between normal colonic mucosa, primary CRC, and metastatic CRC tissue samples. Statistical analyses were conducted using SPSS version 18.0 (SPSS, Inc., Chicago, IL, USA). $p$-Values less than 0.05 were considered statistically significant

\section{Results}

Down-regulation of INPP4B expression in colorectal carcinoma cell lines. Western blotting revealed that INPP4B protein expression was significantly reduced in the CRC cell lines HCT 116, SW620, DLD-1, and WiDr compared to in the normal colonic epithelial cell lines CCD 841 CoTr, and FHC (Figure 1A). Consistent with these findings, quantitative real-time reverse-transcriptase polymerase chain reaction analysis revealed that HCT 116, SW620, DLD-1, and WiDr showed significantly lower INPP4B mRNA expression than CCD $841 \mathrm{CoTr}$ and FHC $(p=0.005$, $p=0.004, p=0.005$, and $p=0.010$, respectively; Figure $1 \mathrm{~B})$.

Down-regulation of INPP4B expression in colorectal carcinoma tissue samples. We investigated INPP4B protein expression in CRC and normal colonic tissue samples by immunohistochemistry (Table I). Representative photomicrographs of INPP4B immunostaining in CRC are shown in Figure 1C. INPP4B immunoreactivity was predominantly 

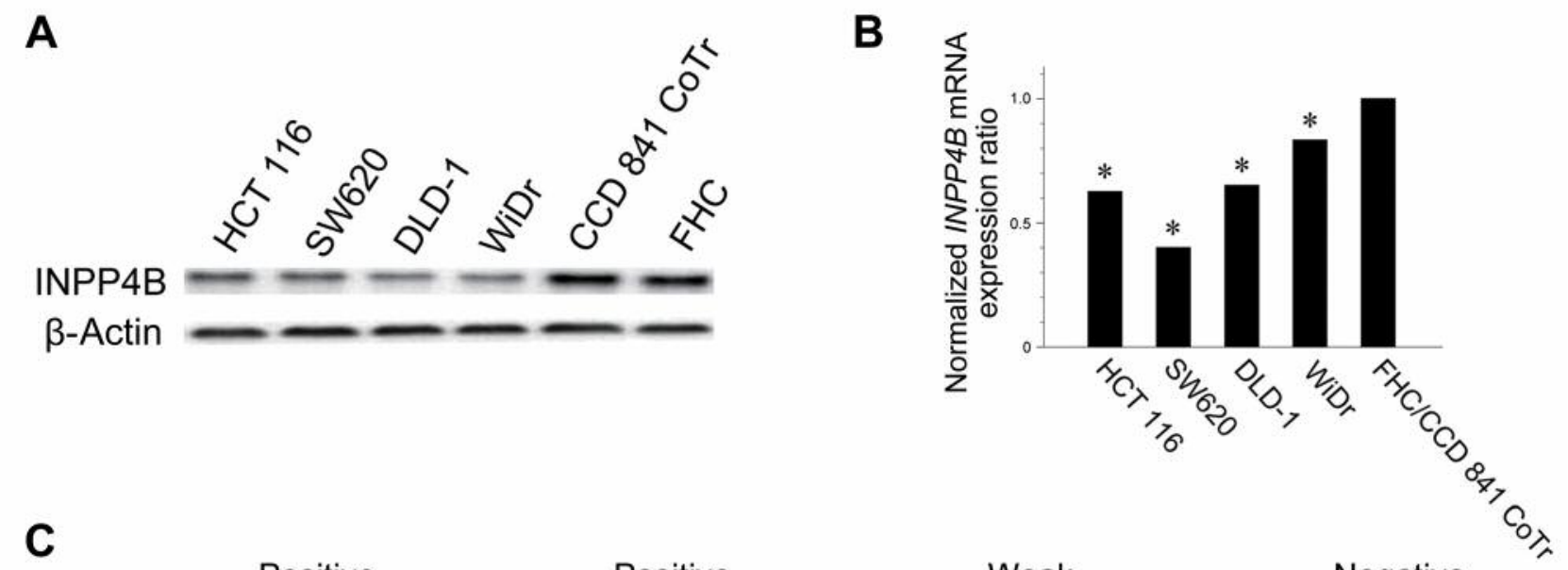

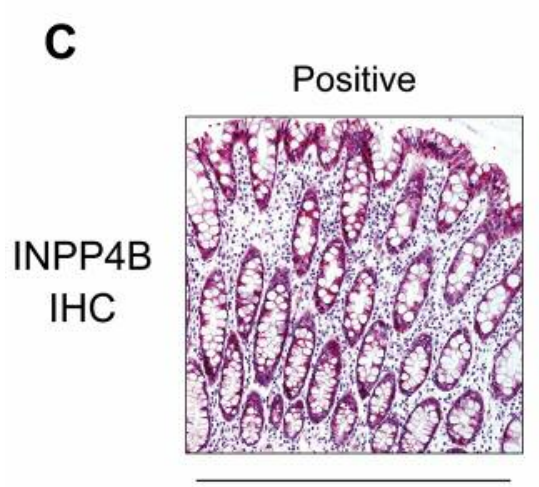

Normal
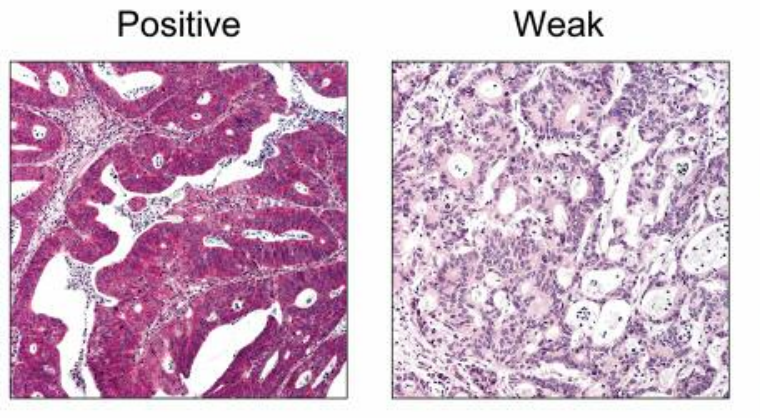

CRC

Figure 1. Inositol polyphosphate 4-phosphatase type II (INPP4B) expression in colorectal carcinoma (CRC). A: Western blot analysis revealed that CRC cell lines HCT 116, SW620, DLD-1, and WiDr exhibited lower levels of INPP4B protein expression than the normal colonic epithelial cell lines CCD 841, CoTr, and FHC. B: Quantitative real-time reverse-transcriptase polymerase chain reaction analysis revealed that CRC cell lines had significantly lower levels of INPP4B mRNA than normal colonic epithelial cell lines. C: Immunostaining for INPP4B in normal colonic mucosa and CRC tissue samples. Original magnification: A-D, 100x.

cytoplasmic, although faint nuclear staining was observed in a few tumor cells. In some cases, weak INPP4B expression was detected in the extracellular matrix or connective tissues. Diffuse and moderate-to-strong INPP4B immunoreactivity was observed in 16 out of the $20(80.0 \%)$ normal colonic tissue samples, while reduced INPP4B protein expression was observed in $60.7 \%(71 / 117)$ of the primary CRC tissue samples. INPP4B expression in primary CRC tissue samples was significantly decreased compared to that in normal colonic tissue samples $(p<0.001)$. Moreover, INPP4B expression in metastatic CRC was significantly decreased compared to that in normal colonic tissue and primary CRC tissue samples ( $p<0.001$ and $p=0.020$, respectively; Figure 2$)$.

\section{Discussion}

Because of the lack of predictive biomarkers for patient stratification, selecting the most beneficial treatment regimen for $\mathrm{CRC}$ remains challenging. In this study, we analyzed the expression of INPP4B in human CRC cell lines and tissue samples. We found that all CRC cell lines examined displayed reduced INPP $4 B$ mRNA and protein levels compared to normal colonic epithelial cell lines. Consistent with these findings, more than half of the CRC tissue samples $(60.7 \%$; 71/117) showed significantly reduced INPP4B immunoreactivity, indicating that INPP4B is a potential diagnostic biomarker for CRC. In addition, reduced INPP4B expression was observed in $76.5 \%(62 / 81)$ of metastatic CRC tissue samples. There were significant differences in INPP4B expression between metastatic CRC and primary CRC tissue samples, indicating that INPP4B down-regulation was associated with CRC progression. Our results indicate that $I N P P 4 B$ down-regulation is involved in the development and progression of CRC and that INPP4B is a novel therapeutic target for the treatment of patients with CRC. 


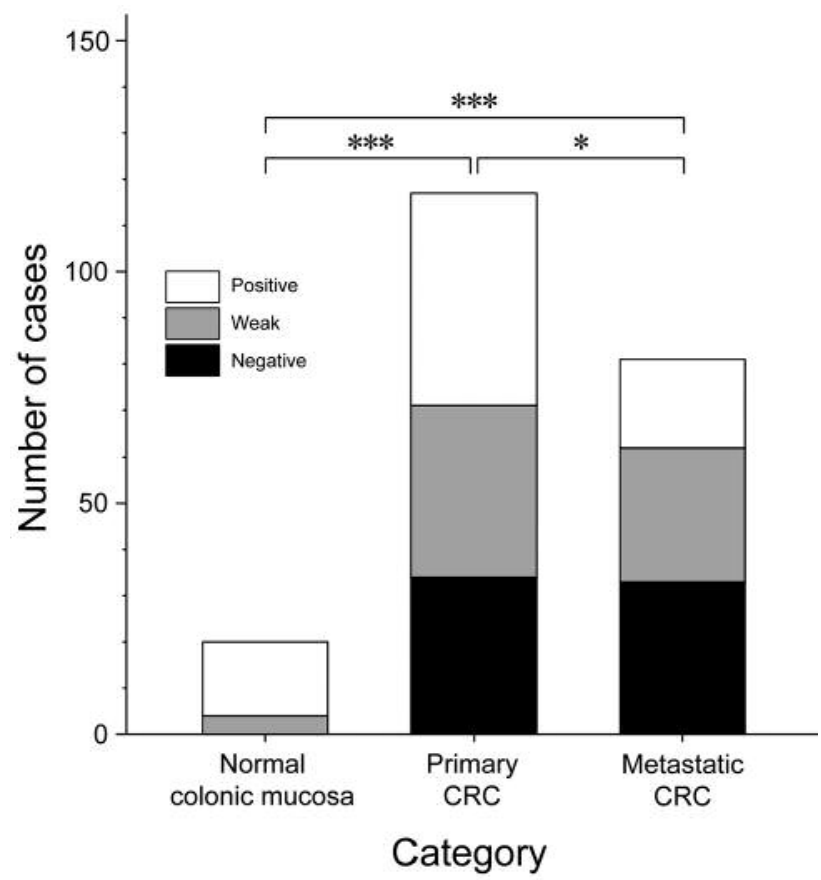

Figure 2. Differences in inositol polyphosphate 4-phosphatase type II (INPP4B) expression between normal colonic mucosa, primary colorectal carcinoma $(C R C)$, and metastatic CRC tissue. INPP4B protein expression of primary CRC was significantly lower than that of normal colonic mucosa. In addition, metastatic CRC exhibited significantly lower INPP4B immunoreactivity compared to normal colonic mucosa and primary CRC. Significantly different at $* p<0.05$ and $* * * p<0.001$.

Previous analysis of the gene-expression profiles of leukemia blasts obtained from 132 patients with pediatric acute lymphoblastic leukemia showed that INPP4B is involved in tumorigenesis (32). Two years later, $I N P P 4 B$ was identified in an RNAi-based genetic screen for genes that suppress the transformation of human mammary epithelial cells, suggesting that INPP4B is a tumor suppressor (33). In subsequent studies, reduced INPP4B expression was observed in breast carcinoma and ovarian carcinoma, and loss of INPP4B expression was found to be associated with decreased patient survival. Particularly, in the breast, loss of INPP4B protein was found to occur most frequently in aggressive hormone receptor-negative, basal-like breast carcinomas, which are generally highly aggressive and show poor clinical outcome. Fedele et al. reported that INPP4B protein expression was lost in $84 \%$ of basal-like carcinomas with higher histological grade, larger tumor size, hormone receptor negativity, and increased proliferative activity (17). Salmena et al. also observed that INPP4B is frequently lost in serous and endometrioid subtypes of ovarian carcinoma and that INPP4B loss is associated with increased mortality (34).
Further studies are needed to examine the clinical and prognostic significance of altered INPP4B expression in CRC.

In contrast, a few previous studies have shown upregulation of INPP $4 B$ expression in malignant tumors. Chi et al. observed that INPP4B was up-regulated in a subset of malignant melanomas. They suggested that INPP $4 B$ functions as an oncogenic driver through the activation of serum- and glucocorticoid-regulated kinase 3 (SGK3) (6). As supporting evidence for this argument, they found that $I N P P 4 B$ knockdown inhibited the proliferation of melanoma cells, whereas INPP4B overexpression promoted the proliferation and growth of these cells. Furthermore, they observed that up-regulation of INPP4B promoted AKT activation in CRC (9) and that the effect of INPP4B on SGK3 and AKT occurred because of inactivation of PTEN by the phosphatase activity of INPP4B. Based on the results of previous studies, alterations in INPP4B expression may differ depending on the cell type or organ studied. The discrepancies between our results and those of Guo et al. (9) may be attributed to differences in reagents and experimental procedures with differing degrees of sensitivity. Although previous results suggest that INPP4B may be targetable in the treatment of CRC with a high level of INPP4B expression, given our observation and the role of INPP4B as a tumor suppressor in other types of cancer, inhibition of INPP4B in vivo needs to be evaluated with great caution (16, 17, 22). Regardless, our results indicate that the role of INPP4B in the pathogenesis of different types of cancer needs to be clearly defined.

Studies of the possible mechanisms causing downregulation of INPP $4 B$ have been reported. Yuen et al. found that INPP4B expression decreased in $49.2 \%(32 / 65)$ of nasopharyngeal carcinoma cases and that promoter hypermethylation was involved in INPP4B down-regulation. Moreover, INPP4B was reduced in nasopharyngeal carcinoma cell lines, and treatment with 5-aza-2'-deoxycytidine, a demethylating agent, restored INPP4B expression (35). These results indicate that $I N P P 4 B$ transcription in nasopharyngeal carcinoma cells is silenced by epigenetic alterations. Similarly, Chew et al. found that treatment of human follicular-like thyroid carcinoma cell lines with 5-aza-2'deoxycytidine increased INPP4B expression by approximately 4-fold, which was accompanied by a decrease in AKT activation (36). Choi et al. found a heterozygous deletion mutation that caused a frameshift mutation in exon 25 of the INPP4B gene in CRC and gastric carcinoma (37). This frameshift mutation would lead to a premature stop of amino acid synthesis in INPP4B protein and thus resembled a typical loss-of-function mutation. Additionally, Chi et al. found that $m i R-494$ and $m i R-599$ suppress INPP4B expression. When miR-494 or miR-599 mimics were introduced into the malignant melanoma cell lines Mel-RM and ME4405, endogenous INPP4B expression was down- 
regulated. Introduction of anti-miR-494 and anti-miR-599 into MM200 and ME1007 cells up-regulated endogenous INPP4B (6). These results suggest that restoration of INPP4B expression through the reduction of specific miRNA expression is a novel approach for treating malignant melanoma. Additional studies are needed to analyze the epigenetic mechanisms that affect INPP4B expression and analyze miRNA expression in various cell types and tissues.

In conclusion, we demonstrated that INPP4B is downregulated in CRC cell lines and tissue samples. Our data suggest that INPP4B is involved in regulating CRC development and progression. Significant reductions in $I N P P 4 B$ expression in CRC suggest that INPP4B is a tumor suppressor. Further studies are required to determine the underlying mechanism and prognostic significance of reduced INPP4B expression.

\section{Acknowledgements}

This research was supported by the Basic Science Research Program through the National Research Foundation of Korea (NRF) funded by the Ministry of Science, ICT \& Future Planning (2017R1A2B4007704) and by the Ministry of Education (2016R1D1A1B03935584), and a Faculty Research Grant of Yonsei University College of Medicine (6-2017-0036).

\section{References}

1 Misiakos EP, Karidis NP and Kouraklis G: Current treatment for colorectal liver metastases. World J Gastroenterol 17: 40674075, 2011.

2 Jemal A, Siegel R, Ward E, Murray T, Xu J and Thun MJ: Cancer statistics, 2007. CA Cancer J Clin 57: 43-66, 2007.

3 Moon A, Do SI, Kim HS and Kim YW: Down-regulation of osteoprotegerin expression in metastatic colorectal carcinoma predicts recurrent metastasis and poor prognosis. Oncotarget 7 : 79319-79326, 2016.

4 Jung KW, Won YJ, Kong HJ, Oh CM, Cho H, Lee DH and Lee $\mathrm{KH}$ : Cancer statistics in Korea: incidence, mortality, survival, and prevalence in 2012. Cancer Res Treat 47: 127-141, 2015.

5 Kim HS, Yoon G, Do SI, Kim SJ and Kim YW: Downregulation of osteoprotegerin expression as a novel biomarker for colorectal carcinoma. Oncotarget 7: 15187-15199, 2016.

6 Chi MN, Guo ST, Wilmott JS, Guo XY, Yan XG, Wang CY, Liu XY, Jin L, Tseng HY, Liu T, Croft A, Hondermarck H, Scolyer $\mathrm{RA}$, Jiang $\mathrm{CC}$ and Zhang $\mathrm{XD}$ : INPP4B is up-regulated and functions as an oncogenic driver through SGK3 in a subset of melanomas. Oncotarget 6: 39891-39907, 2015.

7 Courtney KD, Corcoran RB and Engelman JA: The PI3K pathway as drug target in human cancer. J Clin Oncol 28: 10751083, 2010.

8 Ferte C, Andre F and Soria JC: Molecular circuits of solid tumors: prognostic and predictive tools for bedside use. Nat Rev Clin Oncol 7: 367-380, 2010.

9 Guo ST, Chi MN, Yang RH, Guo XY, Zan LK, Wang CY, Xi YF, Jin L, Croft A, Tseng HY, Yan XG, Farrelly M, Wang FH, Lai F, Wang JF, Li YP, Ackland S, Scott R, Agoulnik IU,
Hondermarck H, Thorne RF, Liu T, Zhang XD and Jiang CC: INPP4B is an oncogenic regulator in human colon cancer. Oncogene 35: 3049-3061, 2016.

10 Colakoglu T, Yildirim S, Kayaselcuk F, Nursal TZ, Ezer A, Noyan T, Karakayali H and Haberal M: Clinicopathological significance of PTEN loss and the phosphoinositide 3-kinase/AKT pathway in sporadic colorectal neoplasms: Is PTEN loss predictor of local recurrence? Am J Surg 195: 719-725, 2008.

11 Franke TF, Kaplan DR and Cantley LC: PI3K: downstream AKTion blocks apoptosis. Cell 88: 435-437, 1997.

12 Majerus PW, Kisseleva MV and Norris FA: The role of phosphatases in inositol signaling reactions. J Biol Chem 274: 10669-10672, 1999.

13 Bozulic L and Hemmings BA: PIKKing on PKB: regulation of PKB activity by phosphorylation. Curr Opin Cell Biol 21: 256261, 2009.

14 Franke TF: PI3K/Akt: getting it right matters. Oncogene 27: 6473-6488, 2008.

15 Steelman LS, Stadelman KM, Chappell WH, Horn S, Basecke J, Cervello M, Nicoletti F, Libra M, Stivala F, Martelli AM and McCubrey JA: AKT as a therapeutic target in cancer. Expert Opin Ther Targets 12: 1139-1165, 2008.

16 Gewinner C, Wang ZC, Richardson A, Teruya-Feldstein J, Etemadmoghadam D, Bowtell D, Barretina J, Lin WM, Rameh L, Salmena L, Pandolfi PP and Cantley LC: Evidence that inositol polyphosphate 4-phosphatase type II is a tumor suppressor that inhibits PI3K signaling. Cancer Cell 16: 115-125, 2009.

17 Fedele CG, Ooms LM, Ho M, Vieusseux J, O’Toole SA, Millar EK, Lopez-Knowles E, Sriratana A, Gurung R, Baglietto L, Giles GG, Bailey CG, Rasko JE, Shields BJ, Price JT, Majerus PW, Sutherland RL, Tiganis T, McLean CA and Mitchell CA: Inositol polyphosphate 4-phosphatase II regulates PI3K/AKT signaling and is lost in human basal-like breast cancers. Proc Natl Acad Sci USA 107: 22231-22236, 2010.

18 Carracedo A, Alimonti A and Pandolfi PP: PTEN level in tumor suppression: How much is too little? Cancer Res 71: 629-633, 2011.

19 Ma K, Cheung SM, Marshall AJ and Duronio V: PI(3,4,5)P3 and $\mathrm{PI}(3,4) \mathrm{P} 2$ levels correlate with $\mathrm{PKB} / \mathrm{akt}$ phosphorylation at Thr308 and Ser473, respectively; PI(3,4)P2 levels determine PKB activity. Cell Signal 20: 684-694, 2008.

20 Ooms LM, Fedele CG, Astle MV, Ivetac I, Cheung V, Pearson RB, Layton MJ, Forrai A, Nandurkar HH and Mitchell CA: The inositol polyphosphate 5-phosphatase, PIPP, Is a novel regulator of phosphoinositide 3-kinase-dependent neurite elongation. Mol Biol Cell 17: 607-622, 2006.

21 Ye Y, Jin L, Wilmott JS, Hu WL, Yosufi B, Thorne RF, Liu T, Rizos H, Yan XG, Dong L, Tay KH, Tseng HY, Guo ST, de Bock CE, Jiang CC, Wang CY, Wu M, Zhang LJ, Hersey P, Scolyer RA and Zhang XD: PI(4,5)P2 5-phosphatase A regulates PI3K/AKT signalling and has a tumour suppressive role in human melanoma. Nat Commun 4: 1508, 2013.

22 Hodgson MC, Shao LJ, Frolov A, Li R, Peterson LE, Ayala G, Ittmann MM, Weigel NL and Agoulnik IU: Decreased expression and androgen regulation of the tumor suppressor gene INPP4B in prostate cancer. Cancer Res 71: 572-582, 2011.

23 Perez-Lorenzo R, Gill KZ, Shen CH, Zhao FX, Zheng B, Schulze HJ, Silvers DN, Brunner G and Horst BA: A tumor suppressor function for the lipid phosphatase INPP4B in melanocytic neoplasms. J Invest Dermatol 134: 1359-1368, 2014. 
24 Livak KJ and Schmittgen TD: Analysis of relative gene expression data using real-time quantitative PCR and the $2^{-\Delta \Delta C t}$ Method. Methods 25: 402-408, 2001.

25 Kim HS, Do SI, Noh BJ, Jeong YI, Park SJ and Kim YW: Expression of phosphorylated extracellular signal-regulated kinase at the invasive front of hepatic colorectal metastasis. Oncol Lett 9: 1261-1265, 2015.

26 Kim HS, Park SJ, Lee KY, Park YK and Kim YW: Reduced Raf1 kinase inhibitor protein expression predicts less favorable outcomes in patients with hepatic colorectal metastasis. Oncol Rep 28: 161-171, 2012.

27 Bae GE, Yoon G, Song YJ and Kim HS: High-grade squamous intraepithelial lesion arising adjacent to vulvar lymphangioma circumscriptum: a tertiary institutional experience. Oncotarget 7: 48120-48129, 2016.

28 Do SI, Yoon G, Kim HS, Kim K, Lee H, Do IG, Kim DH, Chae SW and Sohn JH: Increased brahma-related gene 1 expression predicts distant metastasis and shorter survival in patients with invasive ductal carcinoma of the breast. Anticancer Res 36: 4873-4882, 2016.

29 Park CK, Yoon G, Cho YA and Kim HS: Clinicopathological and immunohistochemical characterization of papillary proliferation of the endometrium: A single institutional experience. Oncotarget 7: 39197-39206, 2016.

30 Yoon N, Yoon G, Park CK and Kim HS: Stromal p16 expression is significantly increased in malignant ovarian neoplasms. Oncotarget 7: 64665-64673, 2016.

31 Yoon G, Koh CW, Yoon N, Kim JY and Kim HS: Stromal p16 expression is significantly increased in endometrial carcinoma. Oncotarget 8: 4826-4836, 2017.

32 Ross ME, Zhou X, Song G, Shurtleff SA, Girtman K, Williams WK, Liu HC, Mahfouz R, Raimondi SC, Lenny N, Patel A and Downing JR: Classification of pediatric acute lymphoblastic leukemia by gene expression profiling. Blood 102: 2951-2959, 2003.
33 Westbrook TF, Martin ES, Schlabach MR, Leng Y, Liang AC, Feng B, Zhao JJ, Roberts TM, Mandel G, Hannon GJ, Depinho RA, Chin L and Elledge SJ: A genetic screen for candidate tumor suppressors identifies REST. Cell 121: 837-848, 2005.

34 Salmena L, Shaw P, Fans I, McLaughlin, Rosen B, Risch H, Mitchell C, Sun P, Narod SA and Kotsopoulos J: Prognostic value of INPP4B protein immunohistochemistry in ovarian cancer. Eur J Gynaecol Oncol 36: 260-267, 2015.

35 Yuen JW, Chung GT, Lun SW, Cheung CC, To KF and Lo KW: Epigenetic inactivation of inositol polyphosphate 4-phosphatase $\mathrm{B}$ (INPP4B), a regulator of PI3K/AKT signaling pathway in EBV-associated nasopharyngeal carcinoma. PLoS One 9: e105163, 2014.

36 Li Chew C, Lunardi A, Gulluni F, Ruan DT, Chen M, Salmena L, Nishino M, Papa A, Ng C, Fung J, Clohessy JG, Sasaki J, Sasaki T, Bronson RT, Hirsch E and Pandolfi PP: In vivo role of INPP4B in tumor and metastasis suppression through regulation of PI3K-AKT signaling at endosomes. Cancer Discov 5: 740$751,2015$.

37 Choi EJ, Kim MS, Yoo NJ and Lee SH: Inactivating frameshift mutation of INPP4B encoding a PI3K pathway phosphatase in gastric and colorectal cancers. Pathol Oncol Res 22: 653-654, 2016.
Received August 23, 2017

Revised September 18, 2017

Accepted September 19, 2017 